\title{
Identification of Chromosomes Involved in Certain Barley Translocations
}

\author{
Ganesh Prasad ${ }^{1}$ \\ Department of Genetics and Plant Breeding, Banaras Hindu University, \\ Varanasi 221005, India
}

Received September 11, 1975

In view of the manifold utility of translocations (Burnham 1962, Burnham et al. 1954, Hagberg 1962, Hanson 1952, Kasha and Burnham 1965a, 1965b, Ramage 1964), work on their production was initiated at this laboratory and several homozygous translocation lines were established through irradiation of dry seeds of barley with gamma-rays and neutrons. In some of these lines, chromosomes involved were identified and breakpoints were located (Das et al. 1971, Dubey 1969). The present paper describes the identification of chromosomes involved in three induced translocations in barley.

\section{Materials and methods}

Three radiation induced homozygous translocation lines in a 6-rowed barley variety $\mathrm{K} 12$, namely, 3047, 3103, and 3104 were crossed with translocation testers obtained from Prof. C. R. Burnham of the University of Minnesota, U. S. A. The tester stocks used were T1-2a, T1-6a, T1-7d, T2-4a, T3-5b, T3-7a and T4-5a. $F_{1}$ plants were grown and sporocytes were collected. Meiosis was studied in PMCs using the acetocarmine smear technique to identify the chromosomes involved in the translocations.

\section{Results and discussion}

The hybrids between homozygous translocation lines and translocation testers show various types of configurations at metaphase $I$ in respect to the chromosomes involved. When the chromosomes involved in unknown translocation line and translocation tester are quite different, two chains or rings of 4 chromosomes are observed (Fig. 1). When one chromosome is common in both translocations, one ring of 6 chromosomes is observed (Fig. 2). On the other hand, when chromosomes involved in both the translocations are the same, bivalents are expected. However, a ring of 4 chromosomes may also be observed if the chromosomes involved are the same but arrangements of the chromosome ends are different (Hagberg 1954, Kasha and Burnham 1965b). When the translocation line is crossed with normal, $F_{1}$ shows chain or ring of four chromosomes (Fig. 3)

1 Present address: Department of Agricultural Botany, S. D. J. Post Graduate College Chandesar, Azamgarh, U. P., India. 
The $\mathrm{F}_{1}$ 's of the crosses of line 3047 with the testers $\mathrm{T} 3-5 \mathrm{~b}$ and $\mathrm{T} 3-7 \mathrm{a}$ showed $2 \odot 4+3$ II at MI (Table 1) which indicated that the chromosomes 3,5 and 7 were

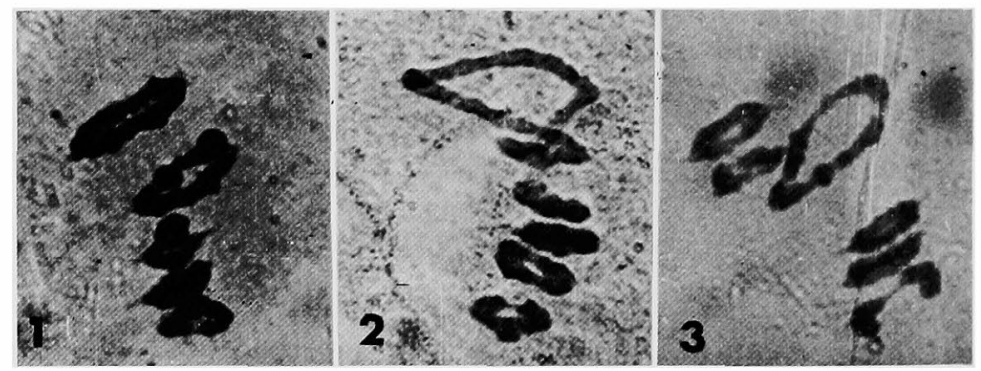

Figs. 1-3. Chromosome configurations in the hybrids of translocation lines and translocation testers. $1,2 \odot 4+3 \mathrm{II}, \quad 2, \odot 6+4 \mathrm{II} . \quad 3, \odot 4+5 \mathrm{II}$.

Table 1. Chromosome configurations in the meiotic cells of $F_{1}$ plants of the crosses of translocation lines with translocation testers*

\begin{tabular}{lccr}
\hline \multirow{2}{*}{ Translocation testers } & \multicolumn{3}{c}{ Homozygous translocation lines } \\
\cline { 2 - 4 } & 3047 & 3103 & 3104 \\
T1-2a & $\odot 6+4 \mathrm{II}$ & $\odot 6+4 \mathrm{II}$ & $2 \odot 4+3 \mathrm{II}$ \\
T1-6a & $\odot 6+4 \mathrm{II}$ & $\odot 6+4 \mathrm{II}$ & $2 \odot 4+3 \mathrm{II}$ \\
T1-7d & $\odot 6+4 \mathrm{II}$ & $\odot 6+4 \mathrm{II}$ & $\odot 6+4 \mathrm{II}$ \\
T2-4a & $\odot 6+4 \mathrm{II}$ & $2 \odot 4+3 \mathrm{II}$ & $\odot 6+4 \mathrm{II}$ \\
T3-5b & $2 \odot 4+3 \mathrm{II}$ & $\odot 6+4 \mathrm{II}$ & $2 \odot 4+3 \mathrm{II}$ \\
T3-7a & $2 \odot 4+3 \mathrm{II}$ & $\odot 6+4 \mathrm{II}$ & $\odot 6+4 \mathrm{II}$ \\
T4-5a & $\odot 6+4 \mathrm{II}$ & $2 \odot 4+3 \mathrm{II}$ & $\odot 6+4 \mathrm{II}$ \\
Standard normal & $\odot 4+5 \mathrm{II}$ & $\odot 4+5 \mathrm{II}$ & $\odot 4+5 \mathrm{II}$ \\
\hline Chromosomes involved & $1-4$ & $1-3$ & $4-7$ \\
\hline$* 4=$ ring of 4 chromosomes & & & \\
๑6 $=$ ring of 6 chromosomes & & & \\
II $=$ bivalent. & & & \\
\end{tabular}

not involved in translocation. On the other hand, $\odot 6+4$ II were observed in crosses with testers $\mathrm{T} 1-2 \mathrm{a}, \mathrm{T} 1-6 \mathrm{a}$ and $\mathrm{T} 1-7 \mathrm{~d}$ and since chromosome 1 was common to all the testers, this chromosome appeared to be involved in the translocation. Again, a configuration of $\odot 6+4$ II was observed when the line was crossed with T2-4a and T4-5a. This suggested that chromosome 4 which was common to both testers was also involved in this line. Thus line 3047 appeared to be T1-4.

Line 3103 showed $2 \odot 4+3 \mathrm{II}$ at M I in the crosses with T2-4a and T4-5a indicating that none of the chromosomes 2, 4 and 5 was involved in this translocation (Table 1). On the other hand, $\odot 6+4$ II in crosses with T1-2a, T1-6a and T1-7d suggested that chromosome 1 was one of the chromosomes of this translocation. Crosses with testers T3-5b and T3-7a also gave $\odot 6+4$ II configuration. Chromosome 3 which was common to both the testers appeared to be the other chromosome of this translocation which was thus T1-3.

In line $3104,2 \odot 4+3$ II were observed with testers T1-2a, T1-6a and T3-5b suggesting that the chromosomes $1,2,3,5$ and 6 were not involved in this trans- 
location (Table 1). However, in crosses with $\mathrm{Tl}-7 \mathrm{~d}$, and $\mathrm{T} 3-7 \mathrm{a}$, a configuration of $\odot 6+4$ II was observed which indicated that chromosome 7 , common to both testers, was one of the chromosomes of this translocation. In crosses with T2-4a and T4-5a again $\odot 6+4$ II suggested that chromosome 4 was apparently involved in this interchange. The line 3104 was, therefore, T4-7.

\section{Summary}

Chromosomes involved in three translocation lines in a 6-rowed barley variety $\mathrm{K} 12$ were identified by studying the meiosis in the hybrids between the translocation lines and Burnham's translocation testers. The chromosomes identified were 1-4 (line 3047), 1-3 (line 3103) and 4-7 (line 3104).

\section{Acknowiedgement}

I wish to express my sincere gratitude to Dr. K. Das for his advice and encouragement throughout the course of this study. Thanks are also due to the I. C. A. R., New Delhi for financial help.

\section{Bibliography}

Burnham, C. R. 1962. Discussions in Cytogenetics. Burgess Publ. Co., Minneapolis, U.S.A. -, White, F. H. and Livers, R. 1954. Chromosomal interchanges in barley. Cytologia 19: 191202.

Das, K., Srivastava, H. M. and Bhowmik, G. 1971. Identification of chromosomes involved in certain interchanges in barley. Nucleus 14: 70-73.

Dubey, K. N. 1969. Cytogenetical studies on some lines of irradiated barley. Ph.D. thesis, Banaras Hindu University.

Hagberg, A. 1954. Cytogenetic analysis of erectoides mutations in barley. Acta Agr. Scand. 4: $472-490$.

- 1962. Production of a duplication of a segment in the short arm of chromosome 6 in barley. Hereditas 48: 243-246.

Hanson, W. D. 1952. An interpretation of the observed amount of recombination in interchange heterozygotes of barley. Genetics 37: 90-100.

Kasha, K. J. and Burnham, C. R. 1965 a. The location of interchange breakpoints in barley. I. Linkage studies and map orientation. Can. J. Genet. Cytol. 7: 62-77.

- and $-1965 \mathrm{~b}$. The location of interchange breakpoints in barley II. Chromosome pairing and the intercross method. Can. J. Genet. Cytol. 7: 620-632.

Ramage, R. T. 1964. Chromosome aberrations and their use in genetics and breedingtranslocations. Barley Genetics 1: 99-115. 